\title{
Structurally Integrated, Damage-Tolerant, Thermal Spray Coatings
}

\author{
ANDREW VACKEL, ${ }^{1}$ GOPAL DWIVEDI, ${ }^{1}$ and SANJAY SAMPATH ${ }^{1,2}$ \\ 1.-Center for Thermal Spray Research, Stony Brook University, Stony Brook, NY 17794-2275, \\ USA. 2.—e-mail: sanjay.sampath@stonybrook.edu
}

Thermal spray coatings are used extensively for the protection and life extension of engineering components exposed to harsh wear and/or corrosion during service in aerospace, energy, and heavy machinery sectors. Cermet coatings applied via high-velocity thermal spray are used in aggressive wear situations almost always coupled with corrosive environments. In several instances (e.g., landing gear), coatings are considered as part of the structure requiring system-level considerations. Despite their widespread use, the technology has lacked generalized scientific principles for robust coating design, manufacturing, and performance analysis. Advances in process and in situ diagnostics have provided significant insights into the process-structure-property-performance correlations providing a framework-enhanced design. In this overview, critical aspects of materials, process, parametrics, and performance are discussed through exemplary studies on relevant compositions. The underlying connective theme is understanding and controlling residual stresses generation, which not only addresses process dynamics but also provides linkage for process-property relationship for both the system (e.g., fatigue) and the surface (wear and corrosion). The anisotropic microstructure also invokes the need for damage-tolerant material design to meet future goals.

\section{BACKGROUND AND INTRODUCTION}

Thermal spray (TS), a melt spray-deposition technology, is widely used to deposit protective coatings on a range of applications where components are subjected to extreme temperature, wear, and corrosive environments. TS coatings are typically thickfilm overlays with coating thicknesses ranging from about 50 micrometers at the low end to millimeter dimensions in select cases. The principle advantage of the process is its versatility in terms of choice of materials, scalability, ability to tailor the microstructures, and capability of depositing onto small and large components with very limited thermal input. TS is now a platform technology servicing a diversity of industries including energy systems (turbines, coal, and fuel cells), propulsion (aeroengines, automotive, and diesel engines), heavy machinery (earth movers and paper mills), electronics manufacturing, and biomedical implants.

In the past, TS coatings were generally introduced as an afterthought in the design cycle, with the principle purpose of providing life extension and protection to advanced and more expensive structural alloys. However, the last decade has seen a shift in their consideration with the goal of using these coatings in prime-reliant function, wherein the component is designed-in with the coatings. Thermal barrier coatings in heat engines and environmentally benign alternatives to electroplated hard chrome are two excellent examples of this approach. In the latter case, driven by the desire to move away from electroplated chrome due to carcinogenic processing by-products, TS coatings have emerged as an attractive alternative to meet performance, cost, and environmental requirements. Typical applications include hydraulic cylinders in earth-moving machinery, aircraft landing gear, paper rolls, pumps, and bearing seals, where a component surface may see a variety of corrosive environments and friction during service. A variety of feedstock materials meant for these overlay coating applications are commercially available, and a particular type of coating composition may be 
selected for use in anticipation of these service environments, based on demonstrated performance aspects of different coating materials.

Despite their widespread acceptance by the engineering industry, incorporation of TS coatings for wear, corrosion, and structural restoration has largely followed a trial-and-error approach. Coating material and application processes tend to be industry and application specific, and they lack a unifying science-based development strategy. The current bill of materials (tungsten- and chromecarbide-based cermets) and processes for wear-resistance applications evolved (adopted) from the early work in the 1960s by the aerospace industry with some tuning to meet industry-specific requirements for each component. Often, these application developments can also be "bottom-up" with coating solutions developed based on experiences and available materials/processes from the sprayapplication industry. The shift to more stringent applications (e.g., aerolanding gear) has raised new design considerations, where the structure-coating system needs to be considered as an integrated entity. The so-called structurally integrated coating concept was introduced by Caterpillar (Peoria, IL) in the early $1990 \mathrm{~s}$; the coating material and process attributes were concurrently considered with component structural requirement. ${ }^{1}$

Several elements of the process need to be included in the design thinking. The coating formation induces complex state of stresses associated with the rapid solidification of the spray droplets (quenching), following which the coating-substrate system can also experience thermal mismatch stresses. These quenching stresses are also affected by material type and process conditions, which affect the thermal energy of the impacting particles. In high-kinetic-energy TS processes (e.g., high-velocity oxy-fuel [HVOF], high-velocity air fuel [HVAF], detonation spraying D-gun, and even noncombustion cold spray processes), there is an additional element of impact induced peening, which can introduce subsurface compressive stresses either on the substrate or on the previously deposited layer. In addition, depending on the part geometry and the processes, many of the TS processes can also contribute significant local thermal effects due to the impinging flame and solidifying particles.

In most heavy industry parts, the controlled tempering/processing of the substrate prior to coating deposition does not make annealing for stress relief from the coating process a viable option. The likely influence of residual stresses on mechanical behavior of coated components, compared with their uncoated state, indicate a necessary inclusion of processing into the coating design, as well as the coating-substrate system design.

\section{Emerging Requirements}

When considering the prospect of treating the coating as a prime reliant contributor to the com- ponent's life and performance rather than just a lifeextension layer, one needs to tally up the key requirements that the TS coatings provide to a similar level of confidence as the structural component. Coating adhesion (to the substrate), cohesion (among the sprayed layers), relevant properties (hardness, toughness), wear and corrosion resistance, and fatigue life of the coated component are all important factors for design consideration. Process-induced effects on the substrate (e.g., formation and residual stresses, and thermal relaxation of shot-peening stresses) are important parameters for consideration that will depend on material, process conditions and even the component-level deposition situation.

The advent of high-velocity deposition processes has allowed the synthesis of cermet coatings with near full density, displaying excellent surface hardness for wear-resistance applications. However, because TS coatings are built in layers, they exhibit a highly anisotropic character even when they display near theoretical density. This anisotropy arises not only from the splat-based layered buildup of the coating but also from chemical decomposition and oxidation of the traveling carbide particles. The decomposition and oxidation can concentrate brittle phases at the interfaces, reducing the toughness of the coating. Wayne et al. ${ }^{2}$ and Usmani et al. ${ }^{3}$ have shown that the in-plane fracture toughness of TS WC-Co coatings can be an order of magnitude lower than that of throughthickness toughness and substantially lower than their bulk counterparts. Usmani et al. ${ }^{3}$ further showed that wear resistance was much more closely coupled to this in-plane fracture toughness rather than coating hardness. By engineering the material (carbide size and binder content) and process (e.g., reducing decomposition and oxidation), it is possible to control some of these coating attributes with concomitant performance benefits. This suggests the need to invoke damage-tolerant design strategies for effective optimization against contact damage.

Finally, many structurally integrated coating applications also require adequate corrosion resistance for system-level function. Beyond the intrinsic corrosion potential of the coating, the coating-substrate system needs to be considered together invoking issues of galvanic compatibility, density, and coating robustness to prevent corrosion ingress to the substrate (e.g., connected porosity and cracks). This sets the requirement for a minimum required thickness at a given density to afford protection.

\section{Opportunity}

The last two decades have seen significant advancements in TS processing hardware and feedstock materials that have enhanced the capability of the technology to meet the stringent design requirements for the proposed class of structurally 
Design Implications for a Structurally Integrated, Damage Tolerant Coating-Substrate System

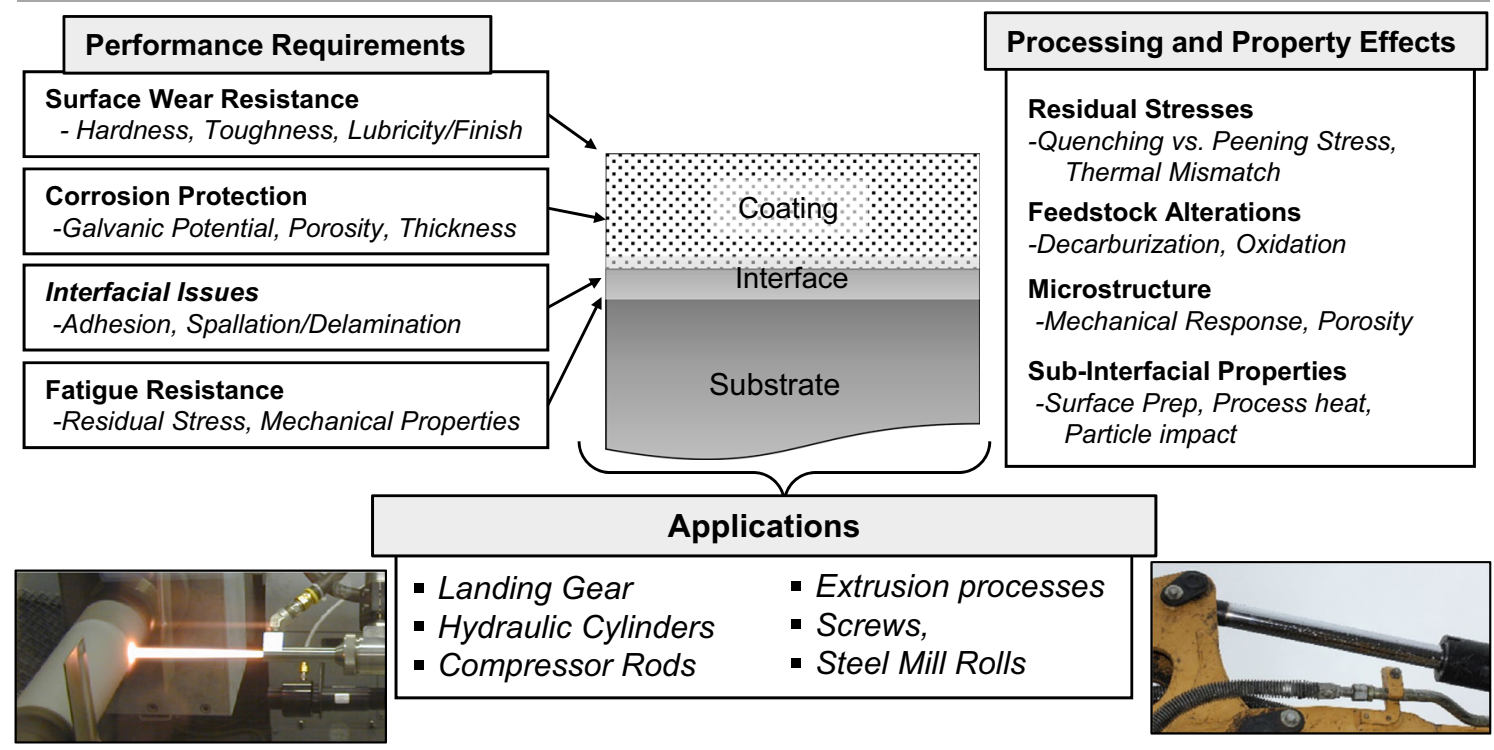

Fig. 1. Key performance and processing factors that affect design and manufacturing of structurally integrated coating systems. Left photo courtesy of Safran Messier-Bugatti-Dowty.

integrated, damage-tolerant coatings. In terms of process hardware advancements, the industry has developed an array of spray devices that allow manipulation of the particle streams, imparting a range of particle thermal and kinetic energies. Advanced mass flow-based control consoles for these torches have enabled greater precision in managing and manipulating gas flows and feedstock introduction, enhancing the reproducibility and control of the spray stream. Integration of robotics has allowed enhanced process precision and application reliability. Several suppliers now offer not only wellcontrolled feedstock powders but also a variety of powders in terms of physical, chemical, and morphological character. These advances are necessary but not always sufficient to meet the goals of prime reliant design and manufacturing of advanced coatings.

Perhaps the most important development in TS technology is an enhanced scientific understanding along with user-friendly diagnostic and characterization tools. Optical sensors that monitor particle thermal and kinetic energies, including their spatial distribution, is now commonplace in most advanced facilities. Combined with sophisticated control systems, they allow day-to-day process repeatability. In recent years, the use of in situ beam curvature measurements during deposition is prevalent in advanced laboratories and being adopted in manufacturing, which provides a first-hand account of coating formation dynamics through extraction of layer-by-layer stress evolution, as well as elastic properties of the deposited coating. ${ }^{4-7}$ All of these sensors have allowed for greater insight into the processing-property-performance correlation, by al- lowing coating specialists to understand the various interplays between the hardware and feedstock selection to what the final coating properties and expected performance are. Such a methodology, termed process mapping, ${ }^{8-10}$ has been a useful tool for rapid optimization of desired coating properties and enables the design for damage-tolerant coatings in a systematic fashion as opposed to a brute force, bottom-up optimization. Coupling the demands for damage tolerant surfaces with the need for considering the coating as structurally integrated in a finished component make for a significant opportunity to produce optimized processing and coatings for high performance engineering components. In this article, we will address several implications that TS processing can have on the final system performance.

Figure 1 lays out key design and manufacturing considerations for a structurally integrated coating system. The coating itself must meet several surface attributes simultaneously in terms of hardness, toughness, surface finish, and density to impart requisite protection. Additionally, the coating must have adequate bond strength to the substrate while ensuring that the substrate mechanical properties are preserved through the processing cycle. These performances are closely tied to TS process parameters, material attributes, and resultant properties. Thus, for each application, the two sides of this coin must be addressed simultaneously. In the following, the various interlinked issues are described in three subsections (Materials and Process Descriptions, Process-Material Interactions, and Property-Performance Linkages) with the goal to identify the critical attributes that address design, manufacturing and performance, and to 
provide insights to both end users of coatings as well as the coating industry supply chain.

\section{MATERIALS AND PROCESS DESCRIPTIONS}

\section{Process Hardware and Feedstock Materials for Structurally Integrated Damage-Tolerant Coatings}

Common TS feedstock materials used for extreme wear and corrosion applications are represented in Table I. The advantage and disadvantages of various compositions are benchmarked in the context of electroplated hard chrome, which has long been used for surface treatment against wear and corrosion. WC-Co cermet composites family (including WC-CoCr to impart better corrosion performance) are the most commonly used wear-resistant TS coatings. $\mathrm{CrC}-\mathrm{NiCr}$ cermets are generally used in less aggressive wear and higher temperature situations. Metallic coatings such as Tribaloys ${ }^{\mathrm{TM}}$ (Kennametal Stellite - Goshen, IN) also find applications in select environments but use of all ceramic coatings is limited. Although each material has certain intrinsic characteristics, the final coating properties and performance are highly processing dependent.

A majority of structurally integrated wear and corrosion coatings are applied via HVOF combustion TS processes. These spray torches project combustion effluents through a converging-diverging nozzle resulting in a supersonic gas stream. This limits the thermal exposure to the particles while simultaneously providing high kinetic energies for compaction. In this processing realm, shown in Fig. 2, coating deposition is achieved through the manipulation of both thermal and kinetic energy of the spray particles. Torch hardware and design provide for different operating spaces; for instance the liquid fuel (LF) HVOF (based on kerosene/jet fuel and oxygen) broadly produces particles with lower temperatures and higher velocities than gas fuel (GF) HVOF. Gas fuel HVOF technologies typically use mixtures of $\mathrm{H}_{2}$ or hydrocarbons and $\mathrm{O}_{2}$ as combustants with the axial injection of the feedstock material through the combustion zone. They generally result in higher particle temperatures. (Certain specialized GF-HVOF torches can melt and deposit ceramics but require very fine particles.) In liquid fuel HVOF, the particles are injected radially

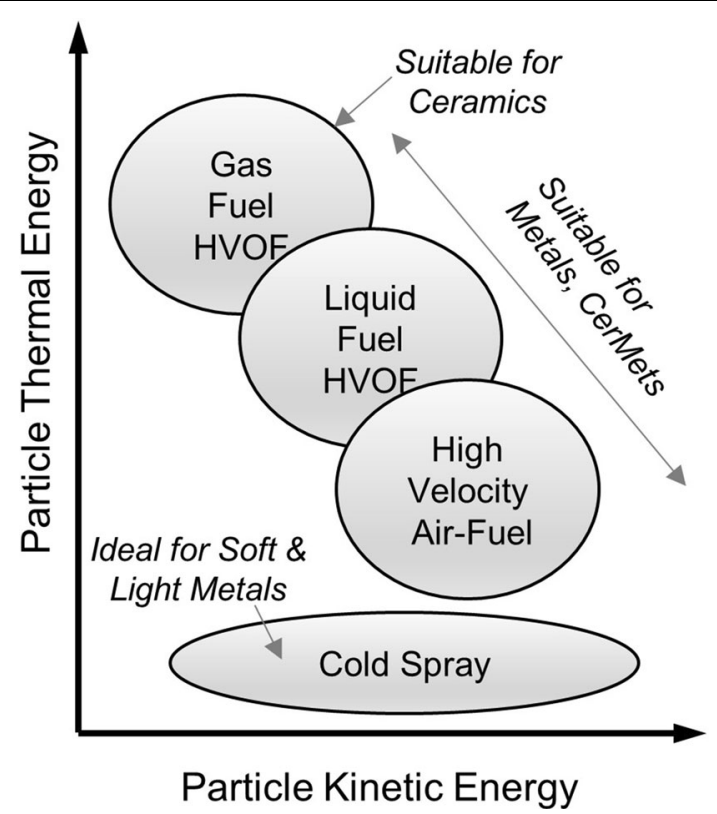

Fig. 2. Thermal and kinetic energy process space for various types of TS processes used in wear coating applications.

Table I. Commonly used overlay coatings used for wear and corrosion applications in structural components identified in Fig. 1 and their characteristics

\begin{tabular}{|c|c|c|}
\hline Material class & Advantages & Disadvantages \\
\hline $\begin{array}{l}\text { Electroplated } \\
\text { hard chrome (benchmark) }\end{array}$ & $\begin{array}{l}\text { - Inexpensive } \\
\text { - Not line of sight } \\
\text { - Easy surface finishing }\end{array}$ & $\begin{array}{c}\text { - Potentially carcinogenic process } \\
\text { - Cracks while depositing } \\
\text { - Delamination failure } \\
\text { • Fatigue debit } \\
\text { - Fails before part }\end{array}$ \\
\hline WC-Co/CoCr & $\begin{array}{c}\text { - Hard, tough, and wear and } \\
\text { corrosion resistant } \\
\text { - Improves fatigue life } \\
\text { - Can last life of part }\end{array}$ & $\begin{array}{l}\text { - Diamond-based surface finishing } \\
\text { is expensive } \\
\text { - Temperature limit of } 450^{\circ} \mathrm{C}\end{array}$ \\
\hline $\mathrm{CrC}-\mathrm{NiCr}$ & $\begin{array}{l}\text { - Lighter and cheaper than WC } \\
\text { - Higher service temperature }\left(850^{\circ} \mathrm{C}\right)\end{array}$ & $\begin{array}{l}\text { • Less hard than WC } \\
\text { - Diamond-based surface finishing } \\
\text { is expensive }\end{array}$ \\
\hline Tribaloys & $\begin{array}{l}\text { - Cheaper than WC } \\
\text { - Excellent tribological properties } \\
\text { - Surface temperature is } \sim 850^{\circ} \mathrm{C}\end{array}$ & $\begin{array}{l}\text { - High processing sensitivity } \\
\text { - Less hard than WC and CrC }\end{array}$ \\
\hline
\end{tabular}




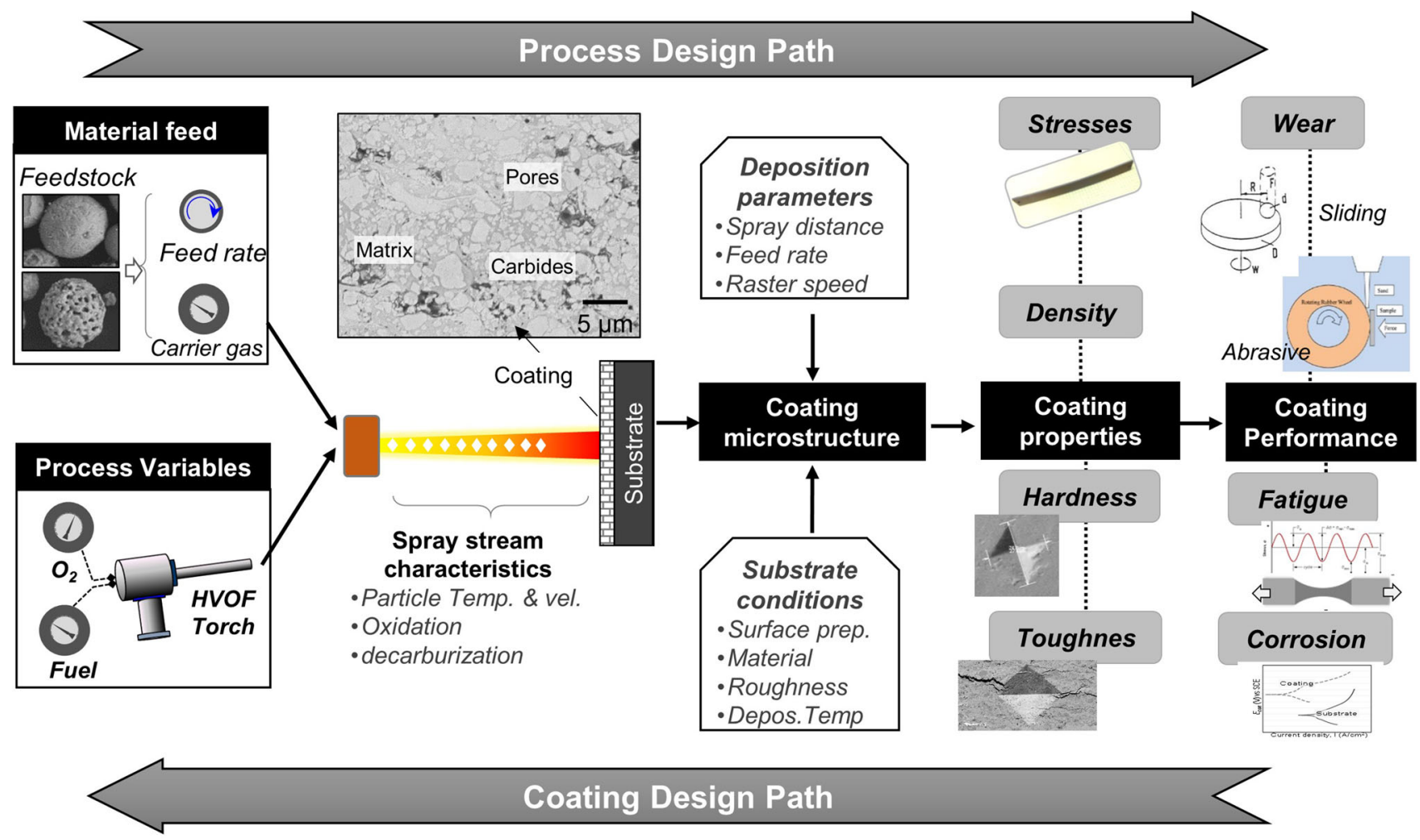

Fig. 3. Illustrative flow chart depicting various process, property, and performance elements that govern process and coating design. Each of the subprocesses are discussed in the subsequent sections of the article with relevance to performance requirements and design elements.

after the combustion zone and convergent-divergent nozzle. The combination of higher gas pressures and particle injection outside the combustion zone results in lower particle thermal energies and higher velocities. In some embodiments, air is used in place of oxygen, $\mathrm{HVAF}$, or via $\mathrm{N}_{2}$ mixing into combustion gas (warm spray), ${ }^{11}$ and it has further limited the thermal heating of feedstock material in an attempt to further limit phase decomposition or oxidation of feedstock material.

Cold spray, relying solely on the heat created by adiabatic shearing of high-kinetic-energy impacted particles to create bonding and deposition, has garnered significant attention as a high-velocity deposition technology with the appeal of little to no alteration of feedstock chemistry. Cold spray has found a niche for the deposition of light and soft metals prone to severe oxidation during deposition (titanium and aluminum), but it has found limited applications for traditional wear-resistant hard coatings.

\section{Understanding and Controlling Process- Particle Interactions: Process Maps}

As shown in Fig. 2, both process type and parametric condition affect the thermal and kinetic properties of the spray particles that, in turn, affect the coating formation dynamics and properties. As noted earlier, with the advent of optical sensors, it is now feasible to quantify particle temperatures and velocities in real time during spraying. ${ }^{12}$ This has allowed both experimental exploration of the process parameters and its effects on particle properties, and it has ensured a high degree of process repeatability and reproducibility. The use of these sensors also enables establishing first-order process maps for TS, where the direct effect of feedstock material, torch hardware, and operating conditions on the spray stream can be visualized. With this knowledge, expanded temperature and velocity maps (e.g., quantified based on melting state and kinetic energy) can be constructed across multiple materials and processes ${ }^{13,14}$ and serve as a guide for tuning process parameters to optimize the desired characteristics of a depositing particle, such as adequate temperature for the melting of the particle or maximizing the velocity for peening intensity and coating compaction.

In addition to particle state, other variables including substrate preparation, deposition rate (feed rate and raster speed), and substrate temperature also contribute to the formation dynamics and final properties of the coating. Overlaying property or performance data with process maps enables establishing process-property zone maps providing a framework for coating designs.

Figure 3 illustratively captures the various elements of the processing that affect coating properties and performance. The control variables are powder type and size distribution and process 

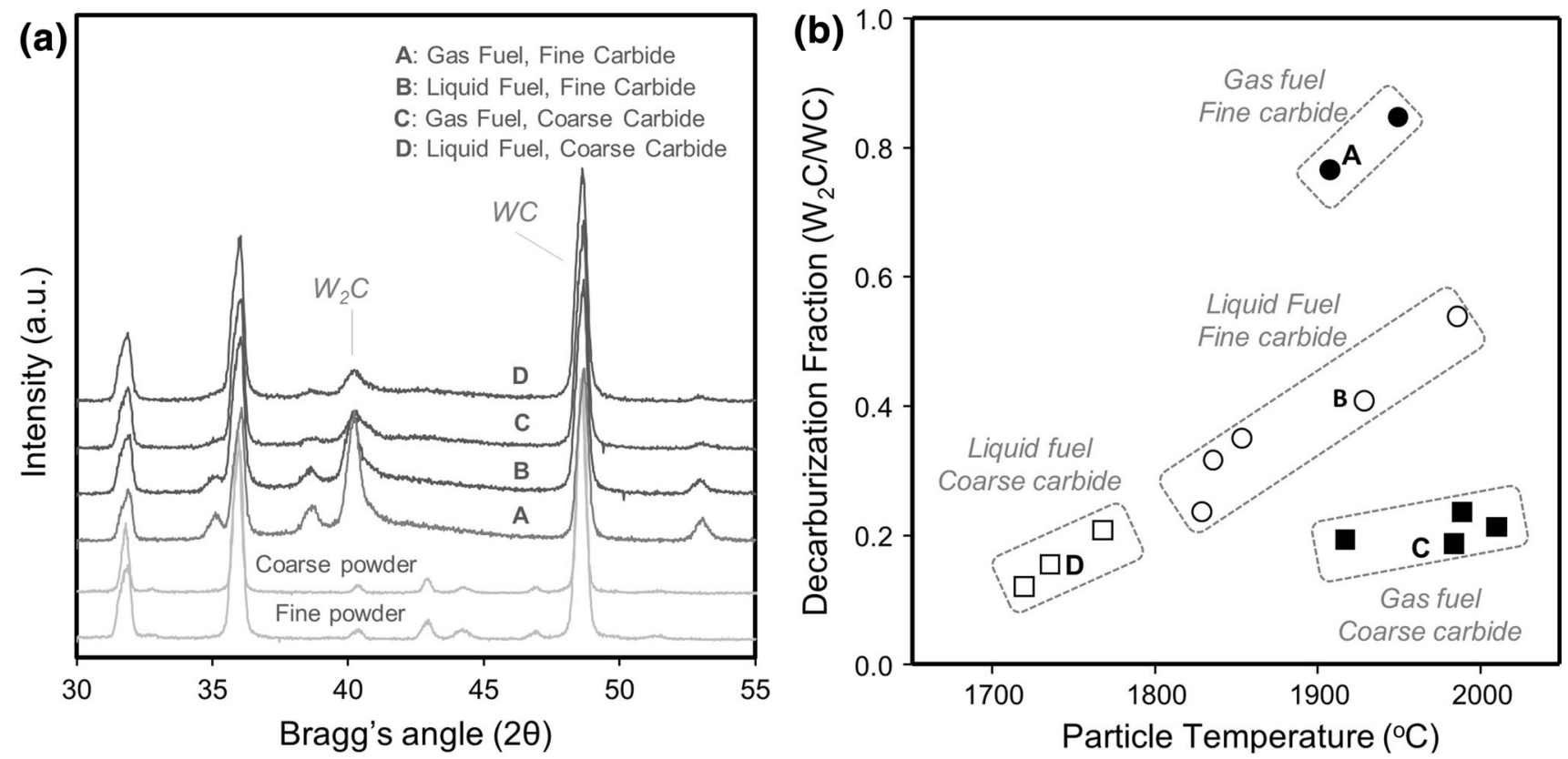

Fig. 4. Analysis of extent of decarburization in HVOF WC-CoCr for various process and material types. (a) X-ray diffractograms show that significant presence of $\mathrm{W}_{2} \mathrm{C}$ phase in fine $(<1 \mu \mathrm{m})$ carbide material, especially those processed via gas fuel torches. The coarse carbide $(1-10 \mu \mathrm{m})$ material is less sensitive to decarburization for equivalent process conditions. (b) The particle temperature is a contributing factor in the decarburization reaction exemplified through the process map of Fig. $1 \mathrm{~b}$ where the ratio of $\mathrm{W}_{2} \mathrm{C} / \mathrm{WC}$ is plotted as a function of measured particle temperature (via optical pyrometry).

conditions (both torch and deposition), whereas the measured outcomes include microstructure, properties, and specific performance tests. The process design path is a forward route for process practitioners (spray applicators, torch and material designers, and researchers) that will provide input to design engineers to specify achievable property requirements for functionality (coating design path).

\section{MATERIALS AND PROCESS INTERACTIONS}

\section{Chemistry and Phase}

The rapid melting (including chemical reactions), impact, and quenching of particles resulting from the TS streams can induce considerable modifications to the phase and composition of the starting feedstock material and thus the final coating. Within the HVOF regime, lower the particle dwell time and thermal exposure, less likely are the alterations to chemistry and phases. The common feedstock materials listed in Table I will undoubtedly experience chemical and structural changes. Carbide containing materials such as $\mathrm{WC}$ and $\mathrm{CrC}$ will experience decarburization (resulting in subcarbide phases) and carbide dissolution into the matrix. ${ }^{15-17}$ In cases of oxidation prone elements ( $\mathrm{Cr}$ for example), excess oxygen within the process or environment can react with the feedstock to produce dispersed oxides within the coating. The rapid solidification traps these metastable states and chemical gradients within the coating, resulting in a highly heterogeneous microstructure. The cer- met compositions are designed to combine the benefits of the hard phase with the metallic matrix to provide optimal combination of hardness and fracture toughness for wear resistance. Degradation of the matrix results in significant loss of coating toughness through dissolution of embrittling phases within the ductile phase. This prevalence of decarburization is not a uniform occurrence within the spraying process and depends on factors related to both feedstock properties, such as the carbide grain size and powder/carbide morphology, as well as the processing-dependent environment the particle experiences, such as plume enthalpy and time of flight for the particle. Thus, understanding and controlling this degradation is of critical importance in optimizing performance.

Figure 4a shows x-ray diffraction results for various WC-Co coatings applied via HVOF. Figure 4b shows the corresponding decarburization map linked to particle temperature. Tertiary phases of $\mathrm{W}, \mathrm{Co}$, and $\mathrm{C}$ are also present but are difficult to isolate and quantify. Several important observations are noted: All of the HVOF processes result in some degree of decarburization. Between the processes, decarburization is lower for liquid fuel HVOF due to material interactions outside the combustion zone. Furthermore, coarse carbide feedstock experiences limited decarburization for both spray systems indicating the importance of carbide surface area within the material. As will be shown subsequently, excessive decarburization is undesirable as they reduce toughness, but some 
degree of decarburization may be beneficial in promoting bonding and also increasing hardness.

Although carbide decomposition and particle oxidation is also important in $\mathrm{HVOF}$ CrC-NiCr, the $\mathrm{x}$-ray diffraction pattern of $\mathrm{CrC}-\mathrm{NiCr}$ coating is not as clear to interpret as the case for WC-CoCr due to considerable overlap of phase peaks of possible $\mathrm{CrC}$ $\left(\mathrm{Cr}_{3} \mathrm{C}_{2}, \mathrm{Cr}_{23} \mathrm{C}_{7}, \mathrm{Cr}_{7} \mathrm{C}_{3}\right), \mathrm{NiCr}$, and chrome oxide. Additionally, there is little difference in XRD patterns between GF and LF HVOF $\mathrm{CrC}-\mathrm{NiCr}$ due to very fine distribution of the oxide phases and dissolved carbides. Mechanistically, the thermal exposure of the particle and carbide size will determine decarburization in a similar way to WC-CoCr. However, the oxidation of the $\mathrm{Ni}$ and $\mathrm{Cr}$ (present in a much higher quantity than in $\mathrm{WC} \mathrm{CoCr}$ ) will be more dependent on the flame stoichiometry, although it is difficult to quantify. ${ }^{14}$

\section{Stress Evolution-Coating Deposition and Residual Stresses}

Processing-induced residual stresses within TS coatings, particularly in the high-velocity process, come from a combination of high kinetic energy impact and the rapid quenching of molten or semimolten particles upon deposition, resulting in net compressive and tensile stresses, respectively. The impact of high kinetic energy particles during coating formation induces a compressive stress into the coating by work hardening or peening the impacting surface, i.e., previously deposited coatings layers (or substrate upon first layer deposition). This peening has been well documented since the inception of high-velocity TS and has the benefits of aiding in coating densification/compaction, as well as negating the tensile, or quenching, stresses accumulated from particle solidification and contraction. Additional stresses are induced after deposition where mismatch in the thermal expansion of the coating and substrate material will result in a thermal stress as the coated part returns to ambient temperature after deposition. The resultant of the peening and/or quenching deposition stress and the thermal stress represents the through thickness residual stress of the coating at ambient temperature.

The ability to quantify the residual stresses of films and coatings was first demonstrated by Stoney in $1909,{ }^{18}$ where the radius of curvature of a coated beam is used to transduce and thus calculate the residual stress within the coating layer. The measurement of in situ beam curvature during TS coating deposition was first demonstrated by Kuro$\mathrm{da}^{5}$ and followed by detailed modeling of the layerby-layer stress building process by Tsui and Clyne. ${ }^{4,19,20}$ The technique was further expanded on by Matijicek and Sampath ${ }^{6,7}$ and correlated with $\mathrm{x}$-ray and neutron-based techniques. ${ }^{21}$ The ability to observe and measure both the coating deposition and cooling gives insight into the coating formation stresses. This so-called evolving stress, calculated by measuring the incremental change in curvature with each layer deposition, ${ }^{14}$ quantifies the net contribution of peening and quenching stresses during coating deposition, which differ with feedstock, process selection, torch operating parameters, deposition rate, and substrate temperature. ${ }^{9,14}$ The use of such an in situ beam curvature method and process knowledge offers the opportunity to tailor a desired coating residual stress.

Figure 5 exemplifies the typical curvature evolution as function of deposited layers during HVOF coating deposition. The deposition portion of the plot can vary greatly as the formation stress is transduced into beam curvature with either a positive or negative slope with coating addition, indicating net tensile or compressive formation stresses, respectively. LF HVOF generally has a shallower curvature versus time slope and, thus, a larger contribution of a compressive stress component than in GF HVOF. This is due to the higher particle kinetic energy and lower thermal soaking of the particles in LF-HVOF, allowing a greater chance of particle peening. The manipulation of parameters, such as fuel and oxygen flow or standoff distance, offers a range of possible intraprocess evolving stresses, and some overlap between GF and LF HVOF is possible. The thermal strain during cooling is determined by deposition temperature and thermal expansion mismatch, and in the case of Fig. 5 (WC CoCr on steel) the thermal strain adds a further compressive component into the coating, regardless of process. Deposition onto different substrates, such as titanium or aluminum alloys, will alter the magnitude of thermal strain and whether the thermal stress component is compressive or tensile.

\section{Particle Kinetic Energy and Peening Intensity}

The mechanisms behind the compressive stress formation in HVOF deposition, or peening intensity, is linked closely to the kinetic energy of the particle during deposition, which has been well documented and quantified using in situ beam curvature measurements for different feedstock materials. ${ }^{9,22}$ In Fig. 6, this peening intensity is captured through the correlation between measured evolving stress and average particle kinetic energy for gas and liquid fuel $\mathrm{HVOF}$ torches. The figure also includes data obtained from measurements with different carbide sizes within the WC-CoCr spray particles. The data corroborate the attributes of the different torches (Fig. 2) and the effects of carbide size. Similar trends are also seen for $\mathrm{CrC}-\mathrm{NiCr}$ although this material tends to be highly sensitive to processing conditions (flame stoichiometry and combustion pressures).

The effectiveness of the peening process via high kinetic energy particles depends on the characteristics of the spray material, its chemical state, and 

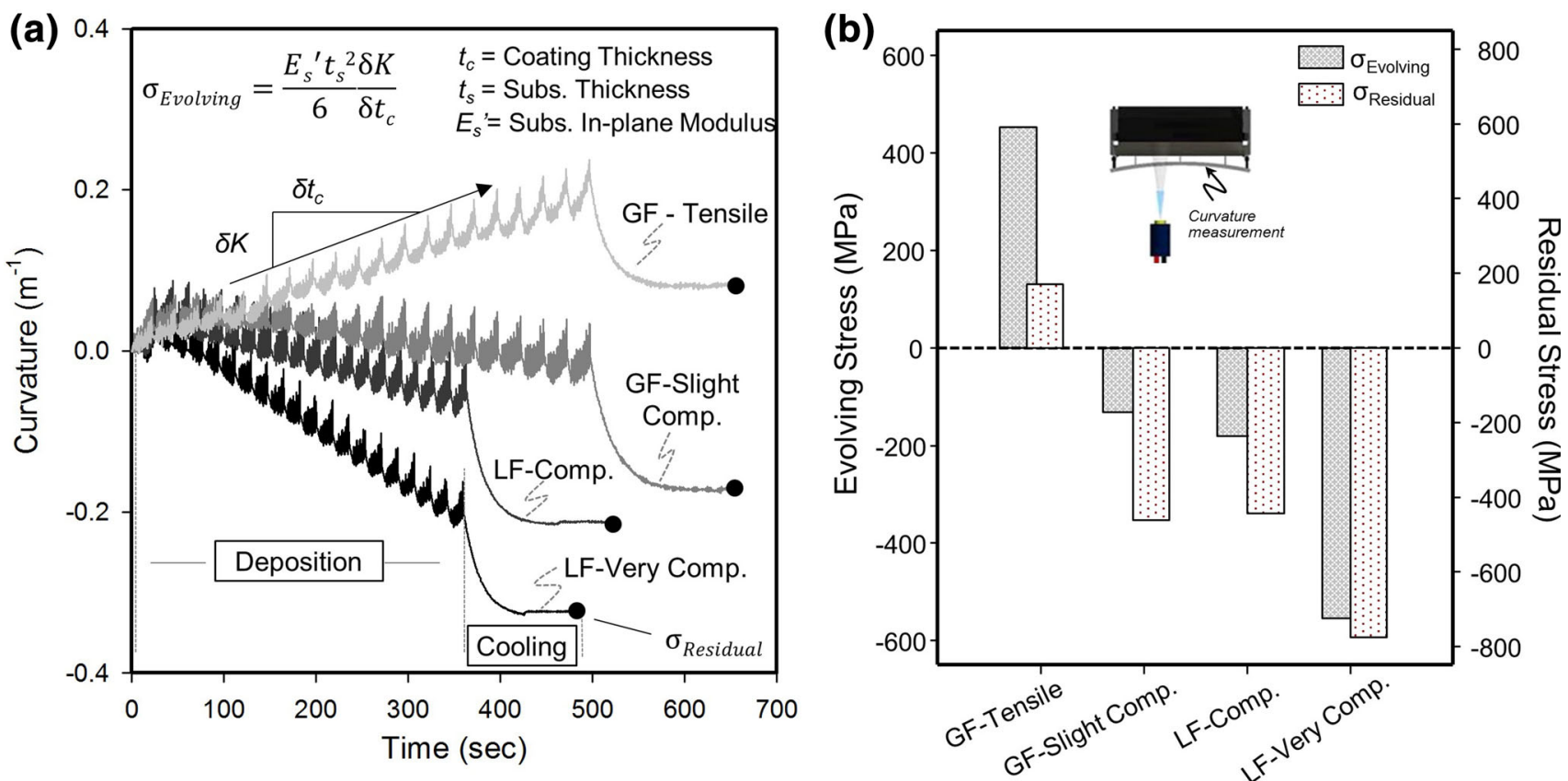

Fig. 5. (a) Depiction of curvature evolution during layer-by-layer HVOF spray deposition of WC-CoCr measured using in situ beam displacement monitoring. ${ }^{6}$ The oscillations are due to rastering of the torch in front of the beam. The slope of the curvature-time graph is termed as evolving stress, ${ }^{14}$ which is a result of particle melting/solidification (quenching stress) and particle impact (peening stress). The $\sigma_{\text {evolving }}$ value is obtained from the Stoney formula. Depending on the torch type and process condition (which affect particle thermal and kinetic energies), evolving stress can be tensile to neutral (for gas fuel torches) and predominently compressive (for liquid fuel torches). Detailed explanations of principles and operative mechanisms are available in the literature. The post-deposition cooling further incorporates thermal mismatch stresses between coating and substrate with the final curvature reporting the residual stress. (b) Values of evolving and residual stresses for the graphs in (a).

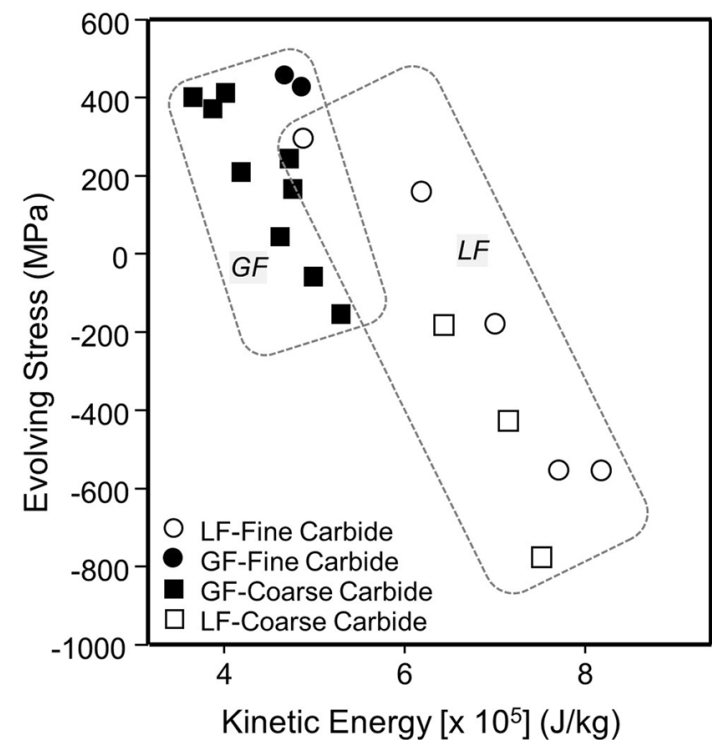

Fig. 6. Relationship between particle kinetic energy and evolving stress for gas and liquid fuel spray processed WC-CoCr with different carbide sizes within the feedstock powder.

process conditions. For instance, materials with larger binder contents (WC-17Co $>$ WC-12Co $>$ WC-10Co4Cr) are more susceptible to peening-induced compression due to greater content of ductile phase. Similarly, the greater the decomposition and carbide dissolution into the matrix, the less likely for the material to support peening. These attributes require consideration in optimizing the coating properties and point to strategies for incorporation within process design to meet different performance requirements.

\section{Microstructures}

Typical optical micrographs of optimized HVOF sprayed coatings usually display near theoretical density. However, scanning electron micrographs of cross-sections reveal the lamellar structure with fine porosity at the interfaces, chemical gradients associated with decarburization, and carbide grain rounding. Figure 7 shows illustrative examples of typical microstructures of the various coatings described in this study. In general, the liquid fuel HVOF coatings (lower row) show higher density and less carbide rounding consistent with the phase analysis. As will be discussed in the subsequent sections, these microstructural nuances affect properties and performance.

\section{IMPLICATIONS ON PROCESS AND PERFORMANCE}

\section{Properties-Hardness and Toughness (in Context of Stress and Chemistry/Phase)}

Microhardness remains a ubiquitous industrial benchmark for assessing the wear performance of spray coatings. However, it is well known that wear 


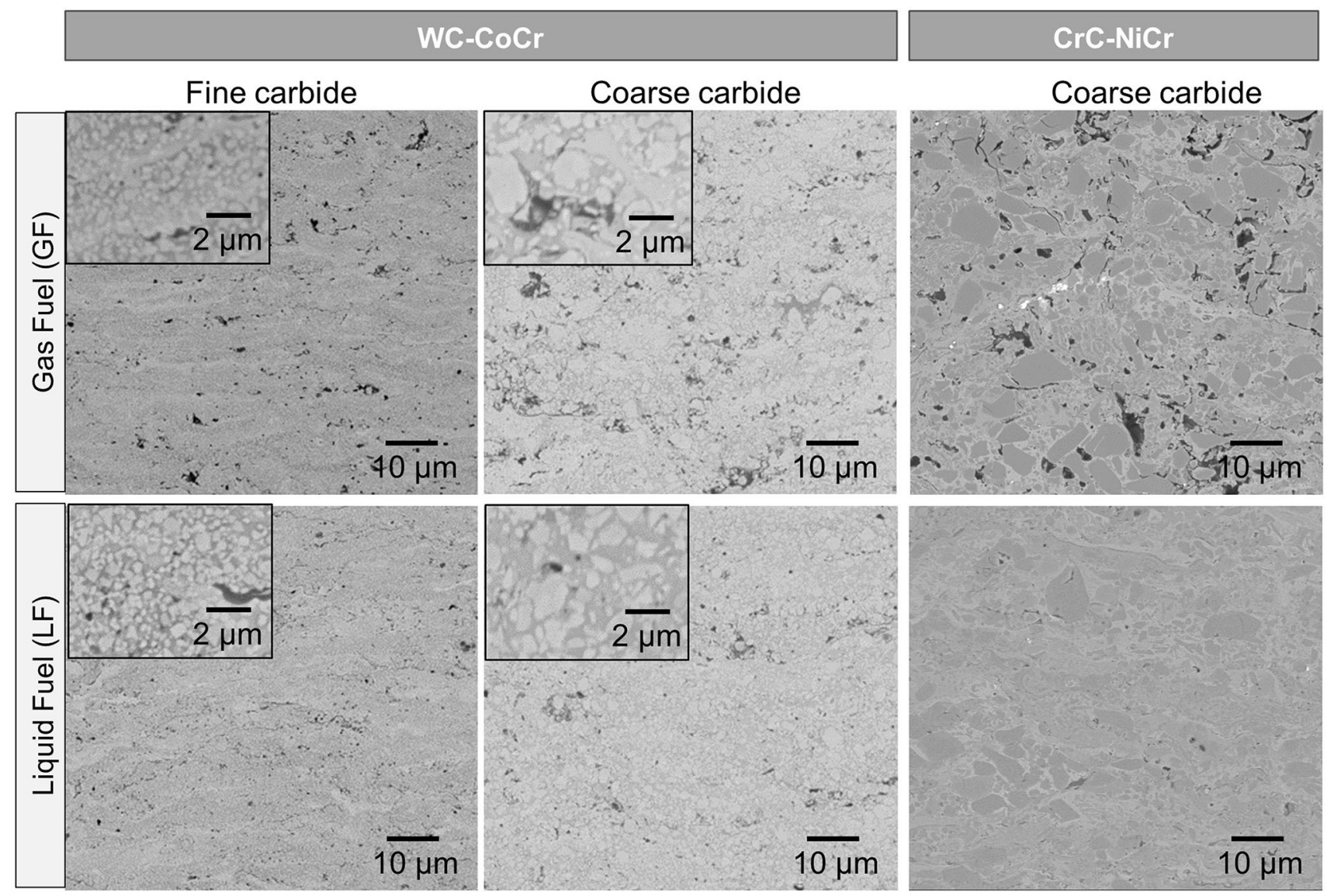

Fig. 7. Backscattered scanning electron micrographs of typical gas and liquid fuel HVOF coatings of WC-CoCr (fine and coarse carbide) and CrC-NiCr. Insets for WC-CoCr shows the difference in carbide size distribution within the lamellae.

of cermets requires a combination of hardness and fracture toughness for effective wear resistance. ${ }^{2,3,23}$ Many factors contribute to the hardness and toughness including intrinsic aspects (carbide size and carbide content) and extrinsic elements (coating density, decarburization, and residual stresses) resulting from strong correlations with processing. ${ }^{9}$ For example, in the case of WC-Co and WC-CoCr, decarburization results in formation of more brittle $\mathrm{W}_{2} \mathrm{C}$ phase engendering higher hardness and lower fracture toughness. Similar effects are possible in $\mathrm{CrC}-\mathrm{NiCr}$, where thermally decomposed carbides along with process induced formation of dispersed oxides can increase the hardness while lowering the coating toughness. The coating hardness can also be affected by the state-of-stress induced by the process. A compressive coating residual stress due to peening and thermal mismatch will further result in increased hardness. In addition, the peening action can also densify the sprayed layers contributing to the enhanced hardness.

Figure $8 \mathrm{a}$ captures the linkages between hardness and residual stresses for HVOF cermet coatings with varying processing histories and chemistry. In general, microhardness increases with compressive stresses; however, the rise in hardness plateaus beyond a certain value implying achieving the intrinsic limit of $\mathrm{HVOF}$ WC-CoCr. Finer carbide in the starting WC-CoCr sprayed with gas fuel, however, displays higher hardness attributable to greater degree of decarburization and concomitant formation of the harder $\mathrm{W}_{2} \mathrm{C}$ phase (Fig. 4). Figure 8b displays similar results for $\mathrm{CrC}$ $\mathrm{NiCr}$, although the trends are not as obvious. Here again, higher kinetic energy results in higher compressive stresses leading to higher hardness; however, process parameters such as $\mathrm{O}_{2} /$ fuel ratio also affects the hardness.

\section{Hardness and Toughness}

As noted at the outset of this article, the performance of these defected, layered, and chemically heterogeneous coatings are prone to substantially low in-plane fracture toughness. Through controlled experiments with different carbide sizes, Usmani et al. ${ }^{3}$ showed that this in-plane toughness of gas fuel HVOF WC-Co was an order of magnitude lower than the through-thickness toughness (both obtained from indentation). ${ }^{3}$ Furthermore, the wear behavior was directly affected by this in-plane toughness value. 

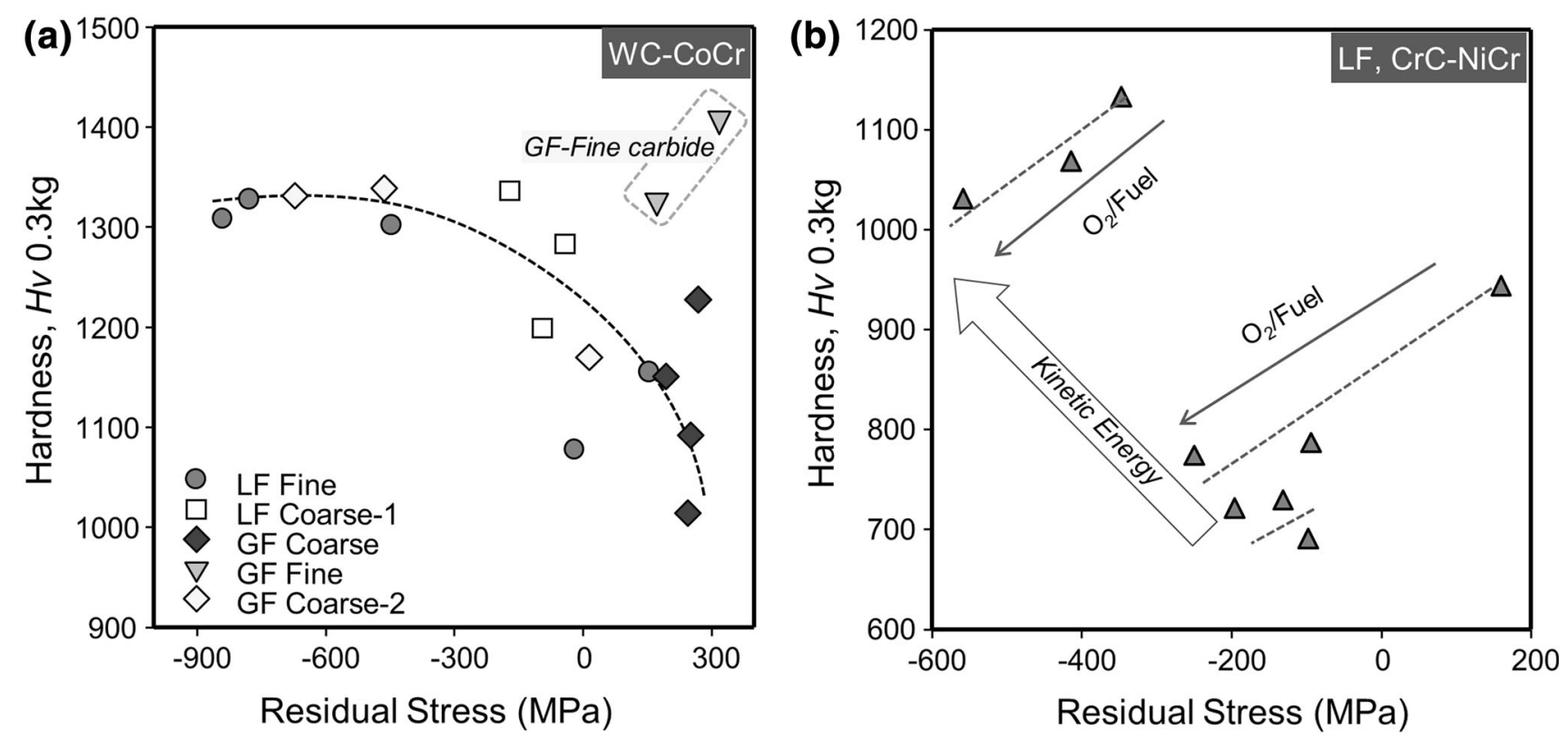

Fig. 8. The relationship between residual stress and Vickers microhardness for (a) gas and liquid fuel HVOF WC-CoCr for various carbide sizes and (b) liquid fuel HVOF CrC-NiCr deposited at various process conditions. Microhardness was measured at a load of $0.3 \mathrm{~kg}$ for $15 \mathrm{~s}$.

Although less common in industrial coating qualification, the indentation fracture toughness method for thin and thick films ${ }^{3,24}$ allows for estimation of the toughness of these coatings. Figure 9 shows an Ashby-type toughness-hardness map for the various types of cermets discussed in Table 1 . Several notable observations can be made with implications for design and manufacturing of damagetolerant coatings.

- Different chemistries cluster at different locations on the map. CrC-NiCr and Tribaloys ${ }^{\mathrm{TM}}$, even heat treated for increased hardness, generally show low hardness and toughness compared with the WC family.

- Among the WC coatings, liquid fuel HVOF coatings with higher compressive stresses resulted in higher hardness while maintaining similar toughness as the gas fuel HVOF coatings.

- However, coatings with larger ductile matrix (12 and $17 \mathrm{Co}$ ) resulted in higher toughness. The implications of these differences on wear are under investigation.

\section{Performance}

\section{Abrasive Wear}

Most of the cermet coatings described in this article are used to protect parent metal against abrasive and erosive wear situations. Laboratory tests such as the ASTM G65 Rubber Wheel Abrasion Test allow benchmarking of abrasive wear performance. Figure 10 compares the abrasive wear behavior of the two classes of HVOF cermets plotted as function of the coating residual stresses. As expected, the

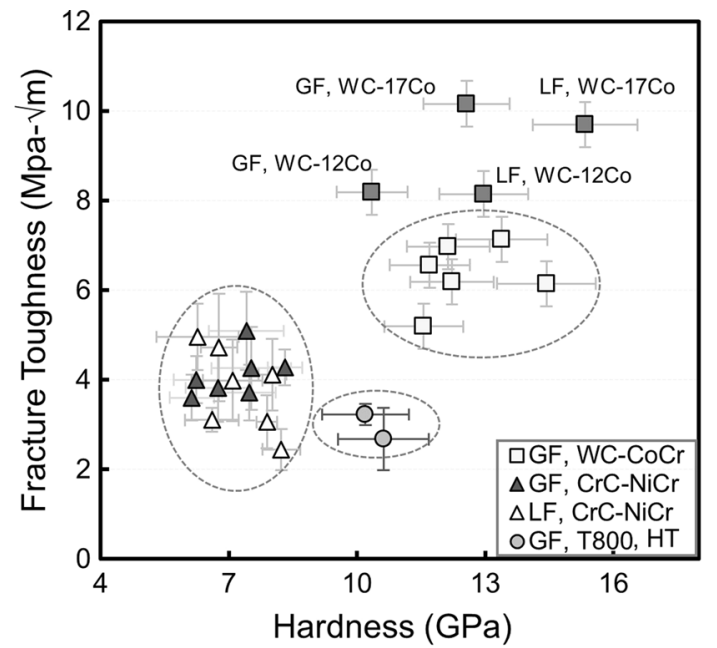

Fig. 9. An Ashby-type toughness-hardness plot developed for common TS damange-tolerate coatings. Hardness was obtained via Knoop indentation and toughness was obtained by Vickers indentation toughness method.

CrC-NiCr with lower hardness and toughness has much less resistance to abrasive wear than the WC$\mathrm{CoCr}$ material. For both materials, there is a general trend of improving wear resistance (reduced volume loss) with a higher level of compressive stresses imparted through higher particle kinetic energy conditions. Another comparison for WC$\mathrm{CoCr}$ shows that the LF WC-CoCr shows an improved wear resistance compared with gas fuel WCCoCr.

The combination of hard carbide and ductile matrix/binder is the key to a damage-tolerant surface. However, for the case of TS coatings, material 


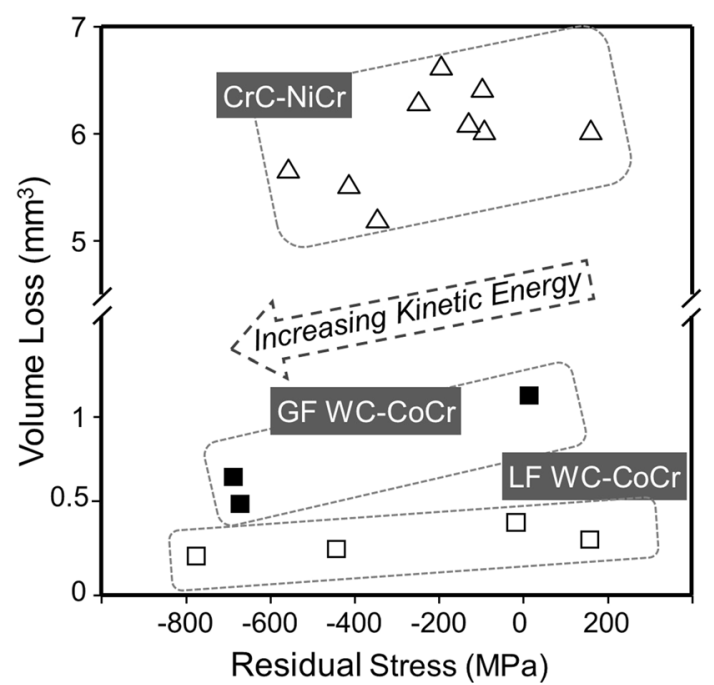

Fig. 10. Abrasive wear volume loss of polished coating surface subject to 20 min wear in an ASTM G65 rubber wheel sand abrasion test plotted as a function of coating residual stresses.

design and process parametrization go hand-inhand to optimize the wear resistance of the surface coating.

\section{Fatigue of Coated Systems}

In addition to wear resistance, there are several applications (e.g., aero landing gear and hydraulic cylinders) in which the coating-substrate system undergo static and cyclic loading requiring understanding of the fatigue behavior of the coated system. As indicated in Table I and Refs. ${ }^{25-27}$, electroplated hard chrome application generally causes some debit to the fatigue life of a component. However, there is no uniform conclusion as to the effect of TS processing on fatigue behavior of the coated system. Substrate surface preparation and residual stress profiles within the coating and substrate play a strong role and both are effected by material choice, process selection, and operating parameters. ${ }^{25-28}$ Understanding and controlling the driving mechanisms within TS coating processing to fatigue life extension offer the unique opportunity to design the coating as a structurally integrated aspect of the part.

Several process steps and mechanisms contribute to the superposition of stresses across the coatingsubstrate profile. Paris' law of subcritical fatigue crack growth relies on stress intensification at crack tips; hence, the compressive or tensile stresses already present within the coating-substrate profile will hinder or aid fatigue crack growth, respectively. Cyclically stressed substrates requiring TS coatings are often shot peened prior to coating application to store compressive residual stress at the substrate material surface, which is the most likely place for fatigue cracks to initiate and propagate. ${ }^{29}$ Surface roughening through grit blasting, which is the a standard surface preparation for enhancing TS coating adhesion, induces compressive residual stresses at the substrate surface, although it is not the primary goal. Initial deposition of high kinetic energy particles will continue to peen the substrate surface, although local heating and possible stress relief of these previous steps may take place. Coating formation stress and resultant residual stress profiles, discussed in "Stress Evolution-Coating Deposition and Residual Stresses" section will be the final superimposed stress to the system.

The processing sensitivity on fatigue life of cermet coated 4340 steel is seen in Fig. 11a (using rotating bending fatigue test), with coatings with different chemistries and stress states (see the "Chemistry and Phase" and "Stress Evolution-Coating Deposition and Residual Stresses" sections). The results show that coatings deposited at a high compressive state of stress shows significant fatigue credit compared with the coatings sprayed under neutral or tensile conditions that show little change over the bare state. Among the two compositions, the compressive WC-CoCr-coated sample shows the highest increase in fatigue life. Similar trends were also observed in a uniaxial tension-compression fatigue test (Fig. 11b) where the fatigue life debits were observed for coatings in tensile or neutral states while only the coatings in compressive states show fatigue life improvement over the metal. These results are preliminary and clearly much more work needs to be done to understand the underlying micromechanisms, but the data indicate the importance of these linkages among substrate conditions, materials, and process parameters. Furthermore, given that TS is a layered manufacturing technology, novel embodiments such as incorporating layer-by-layer manipulation of material chemistry and process conditions will allow location-specific optimization of the properties. ${ }^{30,31}$ Work along these lines is underway.

\section{Corrosion Behavior of Coated Systems}

The protection of the base materials from potential corrosive degradation is another system requirement that damage-tolerant coatings have traditionally addressed. The service environments for coated parts can range in severity, from relatively benign (open atmosphere) to extremely corrosive (chemical processing), and thus a one-sizefits-all approach cannot be employed. Combined effects of wear and fatigue can further accentuate the corrosion process and vice versa; i.e., corrosion can enhance mechanical damage. In the TS field, both incremental modifications to existing chemistries (e.g., $\mathrm{Cr}$ addition to WC-Co) as well as new alloys (amorphous metals) were contemplated with the former adopted as present day industry standard. Although intrinsically these materials are corrosion resistant, their defected nature (connected pores, cracks, delaminations) will invariably allow ingress of corrosive media with further potential for galvanic 

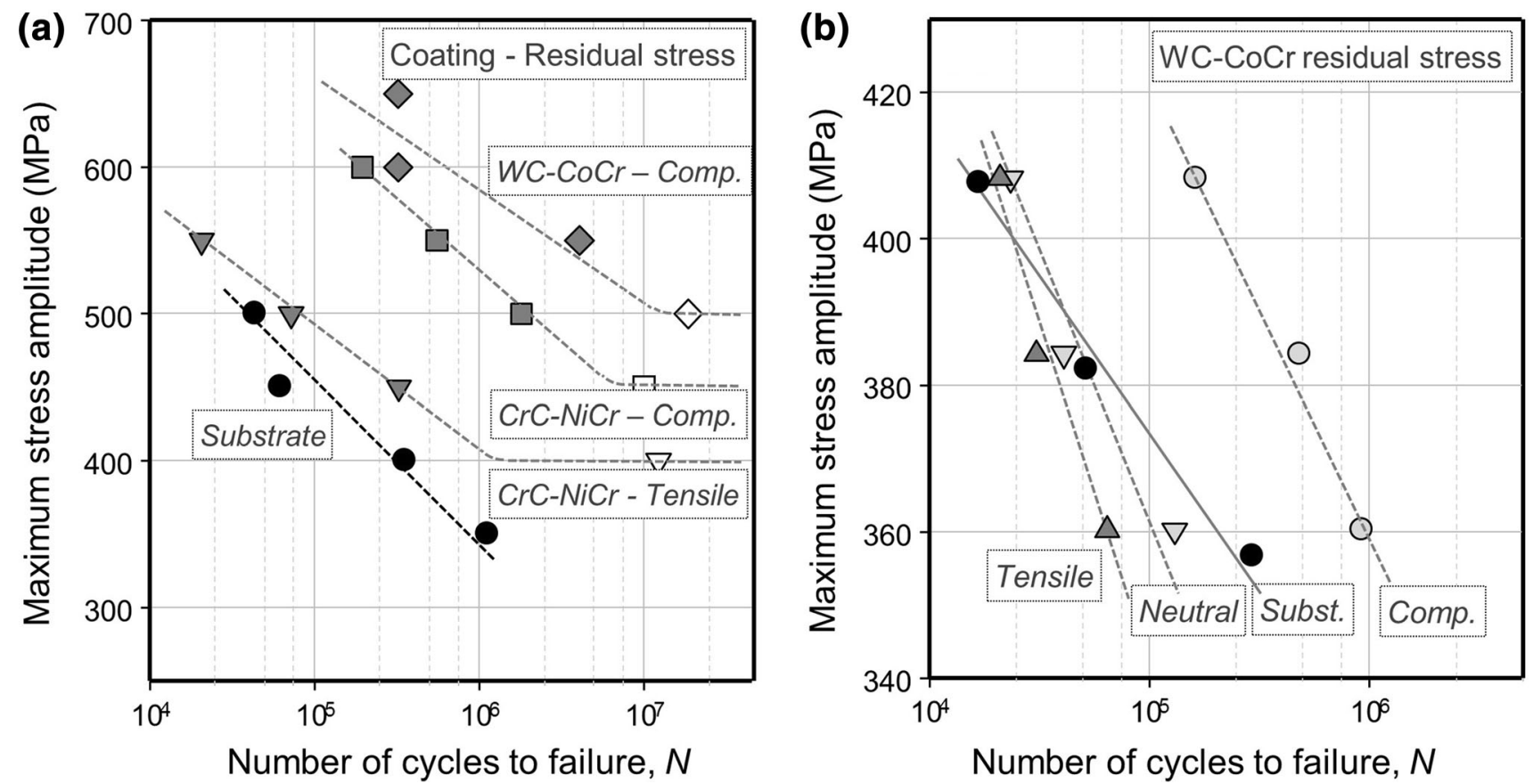

Fig. 11. (a) S-N curves for liquid fuel HVOF-coated 4340 steel obtained from rotating bending fatigue studies. The coatings deposited ith high compressive stresses show higher fatigue life than uncoated and steel and coatings with tensile stresses. (b) Similar S-N curves obtained via uniaxial tension-compression loading obtained for liquid fuel HVOF-coated WC-CoCr onto 1018 steel at different stress states. Added coating thickness to the substrate taken into account for stress calculations in (a) and (b). (Rotating bending data were provided courtesy of Center for Enginering Materials, Tehcnical University at Darmstadt, Germany).

coupling. Thus, corrosion considerations are vital in material and process design, and here again, invoking damage tolerant design is important.

Electrochemical polarization studies and salt exposure are common methods of assessment and benchmarking performance with the former providing quantitative differentiation. Figure 12a shows potentiodynamic polarization curves of the select HVOF coatings along with the benchmarked steel substrate. It is evident that all the three coating shows protective capability. The $\mathrm{CrC}-\mathrm{NiCr}$ (A) coating showed better corrosion potential than the two WC-CoCr coatings. The data suggest that coatings with greater decarburization (fine carbideC) are less effective.

Although Fig. 12a exhibits a material-based assessment of the three coatings, additional effects of their processing conditions are revealed in Fig. $12 \mathrm{~b}$, which constructs a version of possible design map for damage-tolerant coatings. Here, the corrosion potential $\left(E_{\text {corr }}\right)$ is plotted against the residual stresses in the coatings. As mentioned, this stress is also a key parameter affecting mechanical performance of the coatings. The figure reveals that although $\mathrm{CrC}-\mathrm{NiCr}$ has intrinsically better corrosion potential, nonoptimal processing can deem the coating to be less effective. Moreover, when comparing the various $\mathrm{WC}-\mathrm{CoCr}$ coatings, process sensitivity does not seem to be as significant as seen in CrC-NiCr case.
Last, because much of the observed corrosion is due to ingress of corrosive media through the connected porosity, the minimum coating thickness for a given microstructure is a design parameter. Three examples are provided in Fig. 13 comparing different materials and processes. The data reveal that the minimum required thickness to impart corrosion for HVOF coatings ranges from 100 to 200 micrometers. In summary, these examples illustrate the role of fundamental understanding of process property relations in advanced coating design.

\section{SUMMARY AND CONCLUSION}

Thermal spray coatings have and will continue to impact the surface engineering industry. As the capabilities of the technology, materials, process, and diagnostics improve, new opportunities are emerging that will allow robust integration of spray coatings into the design cycle. Pertinent is the emergent requirements for the coating to be structurally integrated (i.e., incorporated into component design), which has created the need for improved coating property measurements, better understanding of the process-property-performance interplay, and investigation into coupled effects of the substrate-coating system. Monitoring and controlling spray particle dynamics and formation stresses has emerged as a key enabler that provides 

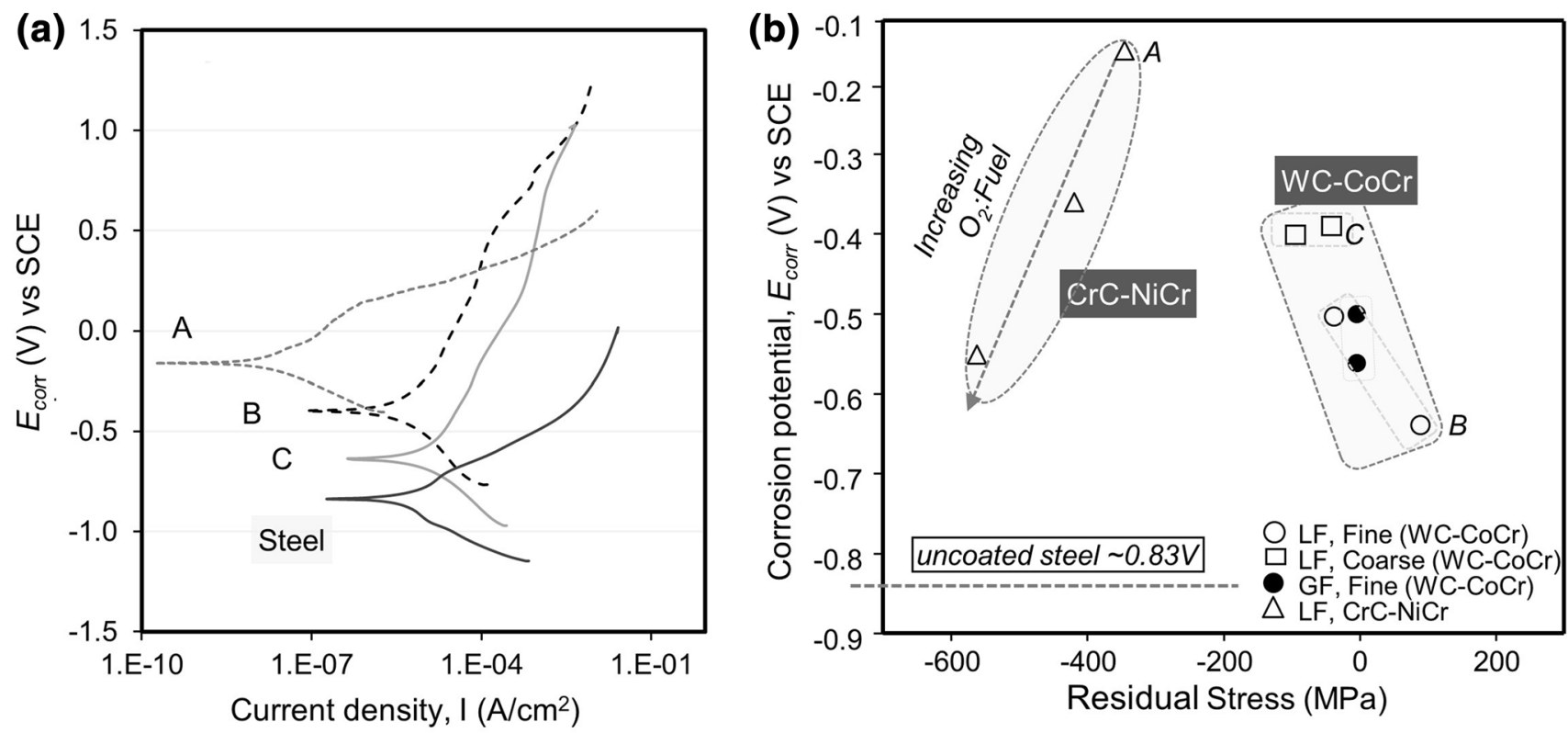

Fig. 12. (a) Electrochemical potentiodynamic measurements (ASTM G61) of exemplary liquid fuel HVOF TS coatings benchmarked with uncoated steel A: CrC-NiCr, B: WC-CoCr coarse carbide, C: WC-CoCr fine carbide. (b) Measured corrosion potential ( $\left.E_{\text {corr }}\right)$ of various coatings mapped as a function of coating residual stress and benchmarked with respect to uncoated steel.

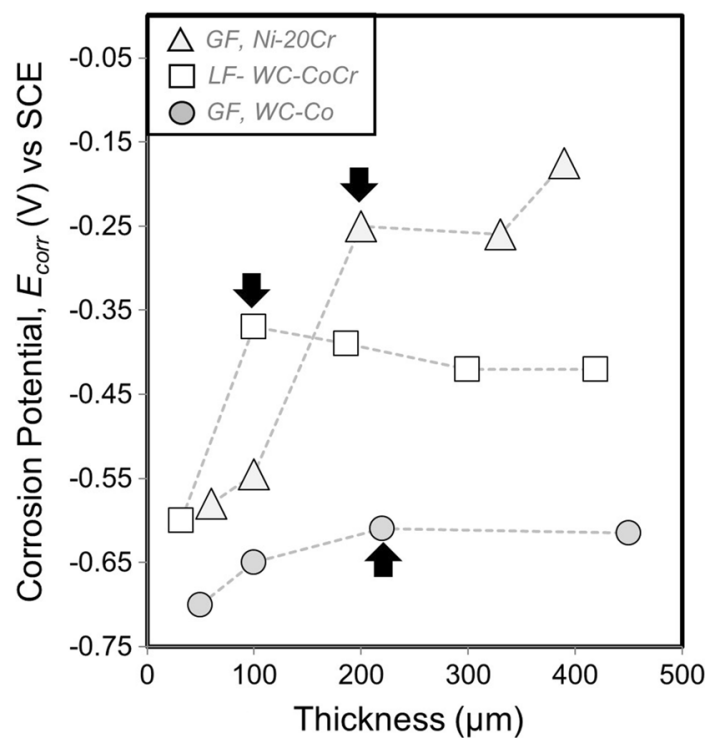

Fig. 13. Measured corrosion potential from ASTM G61 versus coating thickness for NiCr, WC-Co, and WC-CoCr HVOF coatings. The arrows indicate minimum coating thickness for effective corrosion protection (for similar coating densities).

connective coupling among design, materials, process, and performance.

This overview lays out the guiding principles that govern the process-material-property linkages that will define the requisite input for both design and performance assessment. Through integrated and exemplary studies on widely used hardfacing compositions (WC-Co, WC-CoCr, and $\mathrm{CrC}-\mathrm{NiCr}$ ) subjected to a range of process conditions, this article seeks to correlate relevant performance outcomes (wear, fatigue, and corrosion) with process-induced microstructure, phase, and properties. The studies point to the critical role of process-induced residual stresses that affect both system-level attributes (e.g., fatigue) as well surface/coating functionality (wear and corrosion). Of importance also is the need for damage tolerant design considerations due to toughness dominated effects on the contact damage performance of the coatings. It is envisioned that the scientific themes outlined in this paper along with some of the identified correlations will provide industry the impetus for expanded use of structurally integrated damage-tolerant coatings in a variety of applications.

\section{ACKNOWLEDGEMENTS}

The authors are grateful to large number of contributors to the development of this subject matter at Stony Brook, including Chris Weyant, Ari Sagiv, Alfredo Valarezo, Brian Choi, Arash Ghabchi, Ravi Dey, Sal Marino, Saifi Usmani, Jonathan Gutleber, Lubos Prchlik, and Dmitrios Zois. Collaborative interactions with Tommi Varis, Kenneth Holmberg (VTT Finland), David Lee (Kennametal Stellite), Brad Beardsley (Caterpillar), and Thomas Wolfe (Global Tungsten) is gratefully acknowledged. The rotating bending fatigue data shown in Fig. 11a was provided by Norbert Schneider, Brita Pyttel, and Matthias Oechsner from the Center for Engineering Materials at the Technical University of Darmstadt, Germany. A.V. is grateful for financial support from Messier-Bugatti-Dowty Co. for his Ph.D. work on this subject. The financial support to the Center through the Consortium for Thermal Spray Technology program is gratefully acknowledged. 


\section{REFERENCES}

1. M.B. Beardsley and J.L. Sebright, DOE/GO14037 (2008).

2. S. Wayne and S. Sampath, J. Therm. Spray Tech. 1, 307 (1992).

3. S. Usmani, S. Sampath, D.L. Houck, and D. Lee, Tribol. Trans. 40, 470 (1997).

4. Y.C. Tsui and T.W. Clyne, Thin Solid Films 306, 23 (1997).

5. S. Kuroda, T. Fukushima, and S. Kitahara, Thin Solid Films 164, 157 (1988).

6. J. Matejicek and S. Sampath, Acta Mater. 51, 863 (2003).

7. J. Matejicek, S. Sampath, D. Gilmore, and R. Neiser, Acta Mater. 51, 873 (2003).

8. A. Valarezo, W.B. Choi, W.G. Chi, A. Gouldstone, and S. Sampath, J. Therm. Spray Tech. 19, 852 (2010).

9. T. Varis, T. Suhonen, A. Ghabchi, A. Valarezo, S. Sampath, X. Liu, and S.-P. Hannula, J. Therm. Spray Tech. (2014). doi:10.1007/s11666-014-0110-5.

10. A. Vaidya, T. Streibl, L. Li, S. Sampath, O. Kovarik, and R. Greenlaw, Mater. Sci. Eng. A 403, 191 (2005).

11. S. Kuroda, M. Watanabe, K. Kim, and H. Katanoda, J. Therm. Spray Tech. 20, 653 (2011).

12. J. Colmenares-Angulo, K. Shinoda, T. Wentz, W. Zhang, Y. Tan, and S. Sampath, J. Therm. Spray Tech. 20, 1035 (2011).

13. W. Zhang and S. Sampath, J. Therm. Spray Tech. 18, 23 (2009).

14. A. Valarezo and S. Sampath, J. Therm. Spray Tech. 20, 1244 (2011).

15. J. Guilemany, J. De Paco, J. Miguel, and J. Nutting, Metall. Mater. Trans. A 30, 1913 (1999).

16. Y. Qiao, T.E. Fischer, and A. Dent, Surf. Coat. Tech. 172, 24 (2003).
17. C.-J. Li, G.-C. Ji, Y.-Y. Wang, and K. Sonoya, Thin Solid Films 419, 137 (2002).

18. G.G. Stoney, Paper presented at the Proceedings of the Royal Society of London Series A, Containing Papers of a Mathematical and Physical Character, Vol. 82 (1909), p. 172.

19. S. Kuroda and T. Clyne, Thin Solid Films 200, 49 (1991).

20. S. Gill and T. Clyne, Thin Solid Films 250, 172 (1994).

21. J. Matejicek, S. Sampath, T. Gnaupel-Herold, and H.J. Prask, Appl. Phys. A 74, S1692 (2002).

22. S. Kuroda, Y. Tashiro, H. Yumoto, S. Taira, H. Fukanuma, and S. Tobe, J. Therm. Spray Tech. 10, 367 (2001).

23. S. Wayne, J. Baldoni, and S.-T. Buljan, Tribol. Trans. 33, 611 (1990).

24. G. Anstis, P. Chantikul, B.R. Lawn, and D. Marshall, J. Am. Ceram. Soc. 64, 533 (1981).

25. R.T.R. McGrann, D.J. Greving, J.R. Shadley, E.F. Rybicki, T.L. Kruecke, and B.E. Bodger, Surf. Coat. Tech. 108, 59 (1998).

26. M.P. Nascimento, R.C. Souza, I.M. Miguel, W.L. Pigatin, and H.J. Voorwald, Surf. Coat. Tech. 138, 113 (2001).

27. H. Voorwald, R. Souza, W. Pigatin, and M. Cioffi, Surf. Coat. Tech. 190, 155 (2005).

28. O. Kovarik, J. Siegl, and Z. Prochazka, J. Therm. Spray Tech. 17, 525 (2008).

29. M. Torres and H. Voorwald, Int. J. Fatigue 24, 877 (2002).

30. G. Bolelli, V. Cannillo, L. Lusvarghi, R. Rosa, A. Valarezo, W.B. Choi, R. Dey, C. Weyant, and S. Sampath, Surf. Coat. Tech. 206, 2585 (2012).

31. L. Prchlik, S. Sampath, J. Gutleber, G. Bancke, and A. Ruff, Wear 249, 1103 (2001). 